\title{
END OF LIFE IN THE NEONATAL PERIOD: EFFECT OF THE LEONETTI'S LAW ON PRACTICES IN A FRENCH NICU
}

\author{
S. Litzler-Renault, P. Desprez, B. Escande, C. Langlet, J. Matis, D. Astruc, P. Kuhn \\ Hopital de Hautepierre, Strasbourg, France
}

Background: "Leonetti's Law" promulgated in 2005, has clarified medical practices regarding end of life in France. It has prohibited unreasonable obstinacy, has authorized withholding(WHT) or withdrawal(WDT) of treatments (mechanical ventilation, vital drugs, artificial nutrition) when they appeared "useless or disproportionate" and has alleviated pain even at the risk of shortening life. It allowed new reflections and proposals on ethical dilemmas by the French neonatal society which have previously included active ending of life(AEL) in exceptional circumstances.

Aims: To evaluate their impact on end of life practices in NICU.

Methods: Observational retrospective study from medical/nursing charts. Analysis of the number and reasons behind neonatal death, the nature of decisional procedures (WHT, WDT, AEL: classified concurrently by 3 reviewers), analgesia/sedation prescription's, end of life conditions. Comparative analysis (Chi2 test) between 2 periods surrounding the law promulgation, P1(2003-2005), P2(2007-2009).

Results: Number of deaths and NICU admissions stayed stable: 79/1257(P1) vs 93/1267(P2). The proportion of deaths following ethical decision (34/79 vs 53/93, $\mathrm{p}=0.09)$ and WHT actions $(23.5$ vs $41.5 \%, \mathrm{p}=0.09)$ tends to have increased in P2. AEL decisions decreased (53\% vs 3.8\%,p<0.001) whereas WDT increased $(23.5 \%$ vs $54.7 \%, \mathrm{p}<0.01$ in $\mathrm{P} 2)$. The use of titrated doses of analgesic increased (20.6 vs $69.8 \%, \mathrm{p}<0.001)$, while the use of supra-therapeutic doses decreased ( 58.8 vs $5.7 \%, \mathrm{p}<0.001)$ in $\mathrm{P} 2$. The parental presence was similar in both periods.

Conclusions: We noticed quantitative changes in end of life practices after the Leonetti's law promulgation. A qualitative evaluation considering the practice's impact on parental experiences and nursing teams should be performed. 